\section{Sorologia anti-HIV e aconselhamento pré- teste em gestantes na região noroeste do Paraná, Brasil}

\section{HIV serology and pretest counseling among pregnant women in the northwest region of Paraná State, Brazil}

Norico Miyagui Misuta 1

Darli Antônio Soares 2

Regina Kazue Tanno de Souza 3

Tiemi Matsuo 4

Selma Maffei de Andrade 5

Paraná. Secretaria de Estado da Saúde. $15^{\text {a }}$ Regional de Saúde. Maringá, PR, Brasil.

2,3,5 Departamento de Saúde Coletiva. Centro de Ciências da Saúde. Universidade Estadual de Londrina. Av. Robert Koch, 60. Londrina, PR, Brasil. CEP: 86.038-440. E-mail:

soaresda@sercomtel.com.br

4 Departamento de Estatística. Universidade Estadual de Londrina, Londrina, PR, Brasil.

\section{Resumo}

Objetivos: analisar a cobertura do aconselhamento

Objectives: to analyze the coverage of counseling and anti-HIV testing, and to identify factors associated with testing during antenatal care.

Methods: cross-sectional study, with women identified through the information systems in five municipalities in the Northwestern Paraná, Brazil, with deliveries between January to March, 2003. Data was collected during home interviews and an HIV test was considered performed if it could be confirmed in the maternity card or in the reference laboratory records. The $\chi^{2}$ and Fisher exact tests were used in the statistical analysis $(\alpha=0.05)$.

Results: all 435 women who were interviewed had attended prenatal visits, and HIV testing coverage was $89.6 \%$ [95\%CI: 86.8-92.4]. No significant associations were found between HIV testing and variables related to socioeconomic conditions, vulnerability and prenatal care. Although the majority was tested, only $13.6 \%$ reported they had received pretest counseling.

Conclusions: coverage of HIV testing during pregnancy was considered satisfactory. The lack of association between testing and the studied variables indicates that the test is being requested indistinctly as the Ministry of Health recommends. However, the low frequency of counseling and delay in receiving the results may be a sign of problems during prenatal care.

Key words Prenatal care, AIDS serodiagnosis, Acquired Immunodeficiency Syndrome, Counseling e do teste anti-HIV, e identificar fatores associados à sua realização no pré-natal.

Métodos: estudo transversal, com mulheres de cinco municipios do Noroeste do Paraná, Brasil, com partos entre janeiro e março de 2003, identificadas a partir dos sistemas de informação. Os dados foram obtidos em entrevistas domiciliares. Considerou-se teste realizado quando havia registro do resultado do exame para HIV no cartão de gestante ou no laboratório de referência. As análises estatísticas foram feitas utilizando o teste do $\chi^{2}$ e exato de Fisher $(\alpha=0,05)$.

Resultados: das 435 mulheres entrevistadas, todas foram acompanhadas no pré-natal, com cobertura do teste anti-HIV de 89,6\% - [IC95\%: 86,8-92,4]. Não foram evidenciadas associações significativas entre a realização do teste e as variáveis sócio-demográficas, de vulnerabilidade e da assistência pré-natal. Embora a maioria tenha sido testada, apenas $13,6 \%$ relataram ter recebido aconselhamento pré-teste.

Conclusões: a cobertura do teste anti-HIV durante a gestação foi satisfatória. A não-associação entre a realização do teste e as variáveis estudadas sugere que a sua solicitação se dá indistintamente, conforme recomendação do Ministério da Saúde. Porém, a baixa freqüencia do aconselhamento e o atraso no recebimento do resultado dos exames são indicativos de problemas na atenção pré-natal.

Palavras-chave Cuidado pré-natal, Sorodiagnóstico da AIDS, Síndrome da Imunodeficiência Adquirida, Aconselhamento 


\section{Introdução}

A Organização Mundial da Saúde estima que 42 milhões de pessoas estejam convivendo com a Síndrome da Imunodeficiência Adquirida (Aids) no mundo todo, das quais $91,9 \%$ com idades entre $15 \mathrm{e}$ 49 anos e, nesse grupo etário, metade são mulheres. Para 2002, a estimativa de casos novos era de cinco milhões, com cerca de 800.000 ocorrências em crianças. ${ }^{1}$

No Brasil, observou-se aumento da incidência de Aids na população feminina, e o incremento das taxas nesse grupo tem sido nove vezes superior ao verificado entre os homens. ${ }^{2}$ A participação proporcional das mulheres acima de 13 anos, entre os casos novos, passou de 5,3\%, em 1983, para $36 \%$, em 2002. Como conseqüência, a transmissão maternoinfantil passa a constituir importante via de infecção entre crianças, e mais de $85 \%$ dos casos de Aids em menores de 13 anos foi devido à transmissão vertical. 3

Essa forma de transmissão pode ocorrer durante a gestação, trabalho de parto e parto ou pela amamentação. Bertolli et al.4 verificaram em Kinshasa, no Zaire, que $23 \%$ das crianças foram infectadas na gestação, $65 \%$ no intraparto e pósparto precoce e $12 \%$ no pós-parto tardio. Um estudo 5 realizado em quatro cidades do Estado de São Paulo (Ribeirão Preto, Campinas, Santos e São Paulo) revelou uma taxa de transmissão materno-infantil, sem qualquer intervenção, de 16,0\%.

Várias estratégias importantes têm sido adotadas para reduzir a transmissão vertical. Uma das mais significativas é conseqüente ao estudo desenvolvido pela equipe Pediatric Aids Clinical Trials Group, que gerou o Protocolo ACTG 076, nos Estados Unidos e na França em 1994, e que demonstrou redução dessa forma de transmissão em aproximadamente 70\%, com a administração da zidovudina (AZT) à gestante infectada. ${ }^{6}$ Estudos posteriores comprovaram, ainda, que a associação entre as recomendações do protocolo ACTG 076 e outras medidas, como cesárea eletiva e/ou introdução de outros anti-retrovirais nas últimas semanas de gestação, pode reduzir o índice para menos de 2,0\%.7-10

O sucesso da prevenção da transmissão vertical depende da identificação da totalidade das gestantes infectadas e de que essa deteç̧ão seja a mais precoce possível. Assim, o Ministério da Saúde, desde 1997, recomenda a realização do teste anti-HIV (Human Immunodeficiency Virus-HIV) em todas as gestantes, acompanhada do pré e pós-aconselhamento, independentemente de referirem ou não comportamento de risco.11 A importância de se atingir cobertura universal é ainda maior ao se considerar que se trata de infecção cuja soroprevalência é baixa em gestantes, ainda que se observe variações de acordo com a localidade. 12-14

Apesar da alta cobertura do pré-natal no Brasil, muitas gestantes deixam de se submeter ao teste anti-HIV, seja por dificuldade de acesso e/ou pela qualidade da atenção. Morimura et al., 15 ao analisarem a cobertura da testagem anti-HIV no pré-natal em Recife, Pernambuco, identificaram, como fatores associados à sua realização, o número de consultas de pré-natal, a escolaridade da mulher e o aconselhamento pré-teste. Destacam como fundamental a garantia do aconselhamento, o oferecimento e o consentimento, assim como o acesso e o sigilo. Esses autores reforçam, ainda, a necessidade de uma melhoria urgente dos serviços, pois, entre as formas de transmissão do HIV, a materno-infantil é a única passível de erradicação completa.

Vasconcelos e Hamann, 16 ao realizarem estudo avaliativo da assistência pré-natal prestada a parturientes HIV positivo e seus recém-nascidos, em quatro capitais brasileiras, destacam a fragilidade do programa brasileiro de redução da transmissão vertical, no que tange à administração e organização dos serviços nos vários níveis de gestão. Ressaltam a necessidade do alcance da cobertura máxima de gestantes, da facilidade para o processamento laboratorial das amostras e a importância dos gestores, profissionais e usuários entenderem as propostas formuladas. Esta responsabilidade, embora seja do Programa Nacional de Doenças Sexualmente Transmissíveis (DST/Aids) do Ministério da Saúde, necessita obrigatoriamente ser compartilhada com a atenção básica e gestores envolvidos.

Assim sendo, visando subsidiar gestores estaduais e municipais na aplicação de medidas efetivas na prevenção dessa forma de transmissão, o objetivo deste estudo foi analisar a cobertura do aconselhamento e do teste anti-HIV, bem como os fatores associados à sua realização, em gestantes residentes na $15^{\text {a }}$ Regional de Saúde, uma das 22 Regiões Administrativas do Estado do Paraná, durante a assistência pré-natal. A hipótese inicial desse estudo era a de que os profissionais de saúde responsáveis pelo pré-natal atuantes nos municípios da $15^{\text {a }}$ Regional de Saúde não estariam solicitando o teste anti-HIV a todas as gestantes, conforme é recomendado, mas de acordo com a percepção deles de risco. 


\section{Métodos}

Trata-se de um estudo transversal, do qual participaram mulheres residentes em municípios que compõem a $15^{\text {a }}$ Regional de Saúde da Secretaria Estadual de Saúde do Paraná, situada na Região Noroeste do Estado do Paraná, Brasil, cujos partos ocorreram nos meses de janeiro, fevereiro e março de 2003. A população total dos 30 municípios que compõem a área da $15^{\text {a }}$ Regional de Saúde foi estimada, para o ano 2003, ano do estudo, em 663.074 habitantes, 17 dos quais 45,8\% residem em Maringá, município sede. A economia predominante na região é a agropecuária, mas, em alguns municípios situados em entroncamentos viários, tem-se observado o crescimento das instalações industriais e de grandes empresas comerciais, atraindo populações de várias regiões brasileiras à procura de novas oportunidades de trabalho.

Pela Norma Operacional Básica de 1996 (NOB/96), dois municípios, Maringá e Mandaguari, já se encontravam na gestão plena do sistema, estando os demais na gestão plena da atenção básica. No Paraná, a Coordenação Estadual de Aids incluiu o exame diagnóstico do HIV na rotina de pré-natal a partir de 8 de agosto de 1997. Maringá, a partir de 1999, passou a receber o incentivo do programa Aids II, o que possibilitou a realização de várias capacitações em conjunto com a $15^{\mathrm{a}} \mathrm{RS}$ e a Universidade Estadual de Maringá, envolvendo, em todas elas, também os profissionais de saúde pertencentes aos 29 municípios da região.

Como referência laboratorial, a região conta com o Laboratório de Análises Clínicas da Secretaria Municipal de Saúde de Maringá, para os usuários residentes em Maringá, e o Laboratório de Ensino e Pesquisa em Análises Clínicas (LEPAC), vinculado à Universidade Estadual de Maringá, que realiza as sorologias para o HIV para usuários dos serviços públicos de saúde dos municípios da região. A coleta de sangue das gestantes nos municípios é realizada pelos laboratórios municipais ou por compra de serviços privados por meio de convênio do Sistema Único de Saúde (SUS). Esses laboratórios conveniados realizam os exames básicos dos municípios conforme cota fixa, com repasse de verba diretamente do Ministério da Saúde. Uma parte do material coletado é aproveitada para a realização dos exames de rotina e a outra é reservada para os exames de HIV, marcador da hepatite B (HBS Ag) e toxoplasmose IgG e IgM, que são encaminhados semanalmente ao LEPAC. Esse laboratório é referência também para outros exames mais especia- lizados e, dependendo do tipo do exame (contagem de CD4 e carga viral), para municípios pertencentes a outras cinco regionais de saúde.

Para o cálculo do tamanho da amostra foi considerada uma prevalência de $50 \%$ de testagem para HIV em gestantes, e um erro na estimativa de $5 \%$, obtendo-se uma amostra de 384 mulheres. Considerando possibilidade de perdas, uma diminuição no erro e a estimativa de nascidos no período de 1 de janeiro a 31 de março de 2003, a amostra foi estimada em aproximadamente 450 mulheres. De acordo com o número de nascidos vivos durante o ano de 2002, os municípios foram estratificados em pequeno porte (até 200 nascimentos/ano), médio porte (201 a 1000 nascimentos/ano) e grande porte (acima de 1000 nascimentos/ano). A partir da estratificação, foram sorteados, procurando-se manter a proporcionalidade no total de nascidos vivos dos estratos, dois municípios de pequeno porte, dois de médio porte e um de grande porte.

As parturientes foram identificadas por meio do Sistema de Informação sobre Nascidos Vivos (SINASC) e do Sistema de Informação sobre Mortalidade (SIM), cujos dados são mensalmente digitados e encaminhados pelos municípios para a Seção de Epidemiologia da $15^{\text {a }}$ Regional de Saúde, até o $10^{\circ}$ dia do mês subseqüente.

As mulheres foram entrevistadas por meio de visitas domiciliares e, em caso de ausência, foram realizados mais dois contatos, em dias e horários alternados. As entrevistas foram realizadas por um autor do presente estudo (NMM), (66,0\% das entrevistas), e por duas técnicas treinadas da Seção de Epidemiologia da $15^{\text {a }}$ Regional de Saúde, utilizandose um formulário estruturado, previamente testado em municípios que não faziam parte da amostra. No final da entrevista, foi solicitado o cartão da gestante ou laudo de exame e conferido se constava a realização do teste anti-HIV e o seu resultado. Na ausência, esses dados foram pesquisados nos registros do laboratório de referência (LEPAC).

Para fins de cálculo da cobertura e análise dos fatores associados, foram considerados como teste realizado somente os casos em que havia registro do resultado do exame para o HIV no cartão de gestante ou no laboratório.

Após a entrevista, em relação às parturientes que foram testadas e atendidas no sistema público, realizou-se o levantamento de dados nas Unidades Básicas de Saúde e nos registros do Laboratório de Referência referentes à data da última menstruação, data da primeira consulta de pré-natal e data da realização do teste de HIV.

Constituíram as variáveis de estudo para fins de 
análise de associação as características sociais e demográficas das parturientes (faixa etária, escolaridade, planejamento da gestação, número de gestações, porte do município), características relacionadas à vulnerabilidade individual (número de parceiros sexuais, uso de drogas injetáveis, uso de preservativos, doenças sexualmente transmissíveis) e características relacionadas à assistência pré-natal (realização do pré-natal, número de consultas de prénatal, fonte de financiamento, aconselhamento para o teste). Foram consideradas como aconselhadas as entrevistadas que referiram ter recebido explicações sobre a importância da realização do teste e foram informadas da existência da quimioprofilaxia para proteger a criança.

A taxa de cobertura da sorologia para HIV em gestantes foi estimada considerando-se, no numerador, as mulheres que realizaram o teste e, no denominador, o total de mulheres entrevistadas, com o respectivo intervalo de $95 \%$ de confiança.

Os dados foram digitados em dupla entrada, conferidos e editados no programa Epi-Info 6.04d.

Foram utilizados para análise das associações, entre a realização do teste e as variáveis selecionadas, o teste qui-quadrado e teste exato de Fisher, em nível de significância de 5\%. Nas tabelas de contingência 2 × 2 foi utilizado o teste do quiquadrado com correção de Yates.

Este projeto foi aprovado pelos Comitês de Ética em Pesquisa da Universidade Estadual de Londrina (Parecer $\mathrm{n}^{\circ} 182 / 02$ ) e da Universidade Estadual de Maringá (Parecer $n^{\circ}$ 077/2002). Todas as gestantes receberam uma explicação detalhada sobre a pesquisa, e as que concordaram com sua inclusão no estudo assinaram o termo de consentimento livre e esclarecido.

\section{Resultados}

No período de 1 de janeiro a 31 de março de 2003 ocorreram 480 nascimentos nos cinco municípios sorteados, sendo 475 nascidos vivos e cinco natimortos. Dos 475 nascidos vivos, oito eram gêmeos, resultando, desta forma, em 467 mães, que, somadas com as dos natimortos, totalizaram 472 mulheres a serem entrevistadas. Destas, 435 (92,2\%) foram entrevistadas. Ocorreram 37 (7,8\%) perdas (uma se recusou a dar entrevista, 16 mudaram para endereço ignorado, 14 não residiam no endereço mencionado ou o endereço não foi localizado e seis não se encontravam em casa, apesar de três tentativas).

Entre as 435 mulheres entrevistadas, a idade variou de 14 a 44 anos e a grande maioria $(74,7 \%)$ tinha menos de 30 anos de idade. A proporção de grávidas adolescentes (<20 anos) foi de 19,8\%. Referiram ter trabalho remunerado $42 \%$ das entrevistadas. Quanto à escolaridade, apenas $0,7 \%$ não tinha nenhum ano de estudo, $42,8 \%$ haviam estudado entre cinco a oito anos e somente $8,3 \%$ cursavam ou haviam concluído curso superior.

$\mathrm{O}$ acesso a informações sobre DST/Aids foi mencionado por 411 mulheres $(94,5 \%$ das entrevistadas) e a televisão foi o veículo mais citado (54\%). Apenas 13,4\% consideraram o serviço de saúde como fonte de informação.

Todas as parturientes entrevistadas referiram ter sido acompanhadas durante o pré-natal e $81,8 \%$ receberam o atendimento pelo Sistema Único de Saúde, nos serviços próprios ou conveniados. O número médio de consultas de pré-natal foi de 6,7 por mulher, mas $8 \%$ consultaram menos de quatro vezes durante a gestação e apenas $52,9 \%$ sete ou mais vezes. A freqüência às consultas foi superior entre as gestantes que utilizaram o sistema privado $(p<0,001)$.

Entre as 435 mulheres entrevistadas, em apenas 13 casos (3\%) não houve possibilidade de confirmar a realização do teste, tanto no cartão da gestante como no laboratório particular, sendo excluídas do cálculo da cobertura do teste anti-HIV e das análises de associações. Para as 422 em que a realização ou não do teste pôde ser confirmada pelos registros, a cobertura foi de 89,6\% (IC95\%: 86,8-92,4). Entre essas, uma mulher recebeu o resultado do exame somente após o parto. Em nenhum caso o resultado foi positivo.

Observou-se ainda que, em quatro dos cinco municípios estudados, em que foi possível obter informação, $73,3 \%$ das mulheres iniciaram o prénatal no primeiro trimestre, entretanto, somente $50,5 \%$ dos exames foram realizados no mesmo período. Em um município não foi possível realizar a coleta dos dados, pela impossibilidade de localizar os prontuários.

De acordo com a Tabela 1, não se evidenciou associação significativa entre a realização do teste e idade, escolaridade, planejamento da gravidez, número de gestações e porte do município. Relativamente às variáveis relacionadas à vulnerabilidade, também não se observou associação significativa. No tocante à assistência pré-natal, não houve diferença estatisticamente significativa entre a taxa de realização da testagem e o número de consultas de pré-natal e fonte de financiamento.

Embora a maioria tenha sido testada, observa-se que apenas 13,6\% relataram ter recebido aconselhamento pré-teste, sem diferença significativa nos 
Distribuição das mulheres segundo as características sócio-demográficas, vulnerabilidade individual, assistência pré-natal e situação de realização do teste para HIV durante a assistência pré-natal - 15 $5^{\text {a }}$ egional de Saúde. Paraná, janeiro a março de 2003.

\begin{tabular}{|c|c|c|c|c|c|c|c|}
\hline \multirow[t]{3}{*}{ Características } & \multicolumn{4}{|c|}{ Realização do teste } & \multirow{3}{*}{$\begin{array}{c}\text { Total } \\
(n=422)\end{array}$} & \multirow{3}{*}{$\begin{array}{c}\text { Estatística } \\
\chi^{2}\end{array}$} & \multirow[t]{3}{*}{ Valor de $p$} \\
\hline & \multicolumn{2}{|c|}{$\operatorname{Sim}$} & \multicolumn{2}{|c|}{ Não } & & & \\
\hline & $\mathrm{n}$ & $\%$ & $\mathrm{n}$ & $\%$ & & & \\
\hline \multicolumn{8}{|l|}{ Idade (anos) } \\
\hline$<20$ & 75 & 87,2 & 11 & 12,8 & 86 & 3,07 & 0,549 \\
\hline 20 a 24 & 112 & 89,6 & 13 & 10,4 & 125 & $(4 \mathrm{gl})$ & \\
\hline 25 a 29 & 96 & 89,7 & 11 & 10,3 & 107 & & \\
\hline 30 a 34 & 58 & 95,1 & 3 & 4,9 & 61 & & \\
\hline 35 ou mais & 37 & 86,0 & 6 & 14,0 & 43 & & \\
\hline \multicolumn{8}{|l|}{ Escolaridade } \\
\hline 0 a 8 anos & 231 & 88,5 & 30 & 11,5 & 261 & 0,56 & 0,453 \\
\hline 9 ou mais & 148 & 91,9 & 13 & 8,1 & 161 & $(1 \mathrm{gl})$ & \\
\hline \multicolumn{8}{|c|}{ Planejamento da gravidez } \\
\hline Não & 225 & 89,3 & 27 & 10,7 & 252 & 0,01 & 0,942 \\
\hline Sim & 153 & 90,0 & 17 & 10,0 & 170 & $(1 \mathrm{gl})$ & \\
\hline \multicolumn{8}{|l|}{ Número de gestações } \\
\hline Primigesta & 146 & 90,7 & 15 & 9,3 & 161 & 1,49 & 0,474 \\
\hline 2 a 3 & 194 & 89,8 & 22 & 10,2 & 216 & $(2 \mathrm{gl})$ & \\
\hline 4 ou mais & 38 & 84,4 & 7 & 15,6 & 45 & & \\
\hline \multicolumn{8}{|l|}{ Porte do Município } \\
\hline Pequeno & 47 & 92,2 & 4 & 7,8 & 51 & 0,57 & 0,751 \\
\hline Médio & 97 & 90,7 & 10 & 9,3 & 107 & $(2 \mathrm{gl})$ & \\
\hline Grande & 234 & 88,6 & 30 & 11,4 & 264 & & \\
\hline \multicolumn{8}{|c|}{ Número de parceiros (últimos 12 meses) } \\
\hline Um & 367 & 89,5 & 43 & 10,5 & 410 & Fisher & $\cong 1,000$ \\
\hline Dois ou mais & 11 & 91,7 & 1 & 8,3 & 12 & & \\
\hline \multicolumn{8}{|c|}{ Número de parceiros (últimos cinco anos) } \\
\hline Um & 269 & 89,4 & 32 & 10,6 & 301 & 0,00 & 0,967 \\
\hline Dois ou mais & 109 & 90,1 & 12 & 9,9 & 121 & $(1 \mathrm{gl})$ & \\
\hline \multicolumn{8}{|c|}{ Usuárias de drogas injetáveis } \\
\hline Usou ou usa & 8 & 100,0 & - & - & 8 & 4,17 & 0,124 \\
\hline Nunca usou & 352 & 90,0 & 39 & 10,0 & 391 & & \\
\hline Não sabe & 18 & 78,3 & 5 & 21,7 & 23 & & \\
\hline \multicolumn{8}{|l|}{ Uso de preservativo } \\
\hline Nunca usou & 180 & 89,1 & 22 & 10,9 & 202 & 5,39 & 0,068 \\
\hline Algumas vezes & 183 & 91,5 & 17 & 8,5 & 200 & $(2 \mathrm{gl})$ & \\
\hline Em todas relações & 15 & 75,0 & 5 & 25,0 & 20 & & \\
\hline \multicolumn{8}{|c|}{ Teve Doenças Sexualmente Transmissíveis } \\
\hline Não ou não sabe & 367 & 89,5 & 43 & 10,5 & 410 & Fisher & $\cong 1,000$ \\
\hline Sim & 11 & 91,7 & 1 & 8,3 & 12 & & \\
\hline \multicolumn{8}{|l|}{ Número de consultas } \\
\hline Até 6 & 179 & 87,7 & 25 & 12,2 & 204 & 1,06 & 0,303 \\
\hline $7 \mathrm{e}+$ & 199 & 91,3 & 19 & 8,7 & 218 & $(1 \mathrm{gl})$ & \\
\hline \multicolumn{8}{|c|}{ Fonte de financiamento } \\
\hline Privado & 59 & 89,4 & 7 & 10,6 & 66 & 0,03 & 0,867 \\
\hline Público & 319 & 89,6 & 37 & 10,4 & 356 & $(1 \mathrm{gl})$ & \\
\hline
\end{tabular}


Distribuição das mulheres segundo financiamento do pré-natal, realização do teste e aconselhamento pré-teste, $15^{\text {a }}$ Regional de Saúde. Paraná, janeiro a março de 2003.

\begin{tabular}{|c|c|c|c|c|c|c|c|}
\hline \multirow[t]{3}{*}{ Características } & \multicolumn{4}{|c|}{ Aconselhamento pré-teste } & \multirow{3}{*}{$\begin{array}{c}\text { Total } \\
(n=422)\end{array}$} & \multirow{3}{*}{$\begin{array}{c}\text { Estatística } \\
\chi^{2}\end{array}$} & \multirow[t]{3}{*}{ Valor de $p$} \\
\hline & \multicolumn{2}{|c|}{ Sim } & \multicolumn{2}{|c|}{ Não } & & & \\
\hline & $\mathrm{n}$ & $\%$ & $\mathrm{n}$ & $\%$ & & & \\
\hline \multicolumn{8}{|c|}{ Financiamento do pré-natal } \\
\hline Público & 45 & 12,6 & 311 & 87,4 & 356 & 1,02 & 0,3117 \\
\hline Privado & 14 & 17,7 & 65 & 82,3 & 79 & $(1 \mathrm{gl})$ & \\
\hline \multicolumn{8}{|c|}{ Realização do teste* } \\
\hline Sim & 53 & 94,6 & 325 & 88,8 & 378 & 1,21 & 0,2720 \\
\hline Não & 3 & 5,4 & 41 & 11,2 & 44 & $(1 \mathrm{gl})$ & \\
\hline
\end{tabular}

* Excluídos 13 casos em que não foi possível confirmar a realização do teste

atendimentos pelo serviço público ou privado (Tabela 2). Não se observou associação significativa entre a realização da testagem e o aconselhamento pré-teste.

Das 376 mulheres que referiram ter feito o teste, $45 \%$ sequer foram informadas sobre este fato e somente tomaram conhecimento da informação pela leitura da requisição, na coleta do material ou após o resultado. Como motivo para a realização do teste, $94,1 \%$ disseram que o fizeram porque o médico pediu, 5,3\% porque consideravam importante para proteger o bebê e $0,6 \%$ suspeitava de possível infecção pelo HIV.

Das 39 mulheres que referiram que não foram testadas, $66,7 \%$ relataram que não o fizeram porque o médico não pediu; $20,5 \%$ porque foram testadas há pouco tempo ou na gestação anterior; $7,7 \%$ pela dificuldade na coleta de sangue e $5,1 \%$ por outros motivos.

\section{Discussão}

O perfil observado quanto à idade e escolaridade assemelhou-se ao verificado no SINASC para a $15^{\text {a }}$ Regional de Saúde, em 2002, que apresentou 73,5\% de mulheres menores de 30 anos, $19,4 \%$ de gravidez em adolescentes e $0,8 \%$ de taxa de analfabetismo. 18 Indica também melhor situação social e econômica das residentes da área de estudo, quando comparada com a situação do país e de algumas regiões brasileiras. Considerando-se a escolaridade como indicador social, acrescido do fato de ser inversamente associada à proporção de gravidez na adolescência, os valores observados são inferiores aos do conjunto do país $(4,14 \%$ de analfabetismo e $23,5 \%$ de idade materna com menos de 20 anos). 19 Corroboram, ainda, a participação das mulheres que exercem atividade fora do lar, bastante superior aos $18 \%$ referidos para Recife. 20

A cobertura do teste para HIV no pré-natal, de $89,6 \%$, foi relativamente alta, superior à estimada no município de Ribeirão Preto, São Paulo, $(68,3 \%), 21$ entre as parturientes atendidas em hospital de Recife, $(75 \%), 15$ mas inferior à verificada em Porto Alegre, Rio Grande do Sul, (97\%). 22

Entre os fatores analisados como possivelmente associados à realização da testagem, a não confirmação da associação esperada com as variáveis sócio-demográficas e com aquelas relacionadas à vulnerabilidade individual e à assistência pré-natal sugere que a solicitação do exame realizou-se indistintamente. A situação descrita está de acordo com as recomendações do Ministério da Saúde, que indica o teste para todas as gestantes, independentemente de qualquer avaliação de risco.

Contrariamente ao observado no presente estudo, alguns serviços têm oferecido o teste de acordo com a sua percepção de risco. Nos Estados Unidos, o teste para HIV foi ofertado mais para as mulheres mais jovens, com menos de 12 anos de estudo, de condição socioeconômica mais baixa, atendidas em serviços públicos e que recebiam benefícios sociais. ${ }^{23}$

Muitos profissionais de saúde, apesar de todas as informações epidemiológicas disponibilizadas pelo Ministério da Saúde e de recomendações de especialistas da área, mantêm a percepção de que a doença está limitada às pessoas com comportamento 
de alto risco. Todavia, estudos mostram mudanças no perfil epidemiológico da Aids. Casos de infecção pelo HIV têm sido detectados em mulheres residentes nas médias e pequenas cidades, em zonas rurais, e sem referência a fatores de risco. 24,25 Remis e Patrick ${ }^{26}$ argumentam que o teste não deve ser feito seletivamente, porque excluiria de $20 \%$ a $30 \%$ das mulheres infectadas.

Embora cerca de $90 \%$ das mulheres tenham sido testadas, a freqüência referida do aconselhamento pré-teste foi muito baixa $(13,6 \%)$, sem diferença entre aquelas que se consultaram durante o pré-natal nos serviços públicos ou privados. Esse resultado é bem inferior aos 39,3\% registrados em atendimentos realizados em 2000 e 2001, em Pelotas, Rio Grande do Sul,22 e aos 71,1\% observados em Barbados, no ano de 2002.27 No estudo realizado em Pelotas, o não aconselhamento esteve associado ao atendimento em serviços públicos, diferentemente do observado no presente trabalho. Todavia, observamse percentuais discretamente diferentes entre as gestantes que se consideraram aconselhadas e os serviços nos quais foram atendidas $(12,6 \%$ do serviço público e $17,7 \%$ do privado).

Há que se destacar que os procedimentos metodológicos adotados para obtenção de dados referentes ao aconselhamento recomendam cautela, pois, por se tratar do relato das mulheres, pode ocorrer viés de memória, e as informações recebidas durante os atendimentos não terem sido valorizadas e, portanto, elas não se perceberam aconselhadas. Entretanto, outras situações são sugestivas da qualidade da atenção no tocante às relações interpessoais e aos aspectos educativos. Neste sentido, reveste-se de importância o fato de, entre aquelas que não se consideraram aconselhadas, $45 \%$ não terem sido informadas sequer da solicitação da testagem para HIV nos atendimentos. Embora o formulário de coleta de dados não contemplasse questões relacionadas ao oferecimento do teste anti-HIV nas consultas de pré-natal, durante as entrevistas várias mulheres referiram que o profissional havia mencionado a obrigatoriedade do teste, conforme confirmam os motivos apontados, com destaque para os $94,1 \%$ que disseram que o fizeram porque o médico pediu.

A ausência de aconselhamento sugere que não foi dada a opção de aceitar ou recusar o teste, nem foi discutida a sua percepção de risco, adoção de práticas seguras, e, caso fossem soropositivas, a importância da quimioprofilaxia e adesão ao tratamento.

O modo como a testagem para HIV se realiza na $15^{a}$ Regional de Saúde, sem o devido aconse- lhamento, não contribui para diminuir a disseminação do vírus entre parceiros sexuais. A mulher soropositiva detectada e encaminhada para um centro de referência receberá todas as informações sobre a doença, com a possibilidade de prevenir a transmissão vertical e a transmissão entre seus parceiros sexuais; contudo, as mulheres soronegativas, que são a maioria, não estão recebendo a devida atenção. Muitas continuam vulneráveis a contrair o vírus por não estarem devidamente orientadas quanto aos riscos e aos mecanismos de prevenção da infecção. Ao desconhecerem sua situação de risco frente à Aids, bem como os seus direitos, mantêm-se passivas e submissas às condutas dos profissionais. Assim, grande parte das gestantes permanece vulnerável à infecção pelo HIV e outras doenças sexualmente transmissíveis.

Embora o resultado negativo em 100\% das mulheres que se submeteram à testagem seja digno de destaque, o percentual de cerca de $10 \%$ das mulheres não testadas constitui preocupação, principalmente ao se considerar a baixa prevalência de infecção entre as gestantes. Em estudos nacionais, são referidas taxas de $1,7 \% 15$ e $2,2 \% 23$ de soropositividade entre as gestantes testadas. A cobertura, apesar de satisfatória, tendo em vista a baixa prevalência da infecção, não permite afirmar que inexistam gestantes infectadas na população estudada, pois a definição do tamanho da amostra levou em consideração a estimativa da cobertura da testagem e não a soroprevalência. Além disso, não foi de alcance do presente estudo conhecer a situação sorológica das mulheres.

A não realização do teste por motivos administrativos, a falha na solicitação e as diferentes condutas de profissionais responsáveis pelo prénatal, somadas ao não recebimento do resultado, o recebimento pouco antes ou após o parto, revelam problemas como atenção pré-natal tardia ou oferta insuficiente de exames.

O início tardio dificulta a identificação de patologias que possam constituir agravos à saúde do binômio mãe-filho e comprometer o tratamento adequado de forma a impedir suas complicações. No caso da gestante soropositiva, a realização do teste para HIV no primeiro trimestre é fundamental, pois o início da quimioprofilaxia e/ou tratamento, quando necessário, deve ser realizado a partir da 14a semana de gestação. 28

A elevada freqüência de gravidez não planejada, a baixa utilização de preservativos, o adequado número de consultas de pré-natal entre as gestantes estudadas, sem acompanhamento do aconselhamento, apontam a necessidade de promover mudanças que 
contribuam para redução de vulnerabilidades, principalmente a individual, que, no conceito de Ayres et al., ${ }^{29}$ diz respeito aos aspectos cognitivos, como acesso às informações corretas e atualizadas e abordagens comportamentais. Assim, o fato de a televisão ser citada como o veículo mais importante de obtenção de informação permite inferir que as ações educativas desenvolvidas pelos serviços têm sido de alcance restrito para a problemática da transmissão vertical. A incurabilidade da doença e a existência de meios profiláticos para evitar a infecção no recémnascido apontam a urgente necessidade de instituir medidas efetivas para abrangência universal das gestantes.

Os dados não confirmam a pressuposição norteadora do estudo, de que os profissionais de saúde estariam solicitando o teste de acordo com o perfil epidemiológico. Mas o fato de quase a metade das entrevistadas afirmarem realização do teste sem terem sido informadas sequer da solicitação, representa um grave problema ético e de violação aos direitos humanos, principalmente ao considerar que a população estudada é constituída em sua maioria de pessoas de baixa escolaridade e acesso limitado às informações. A solicitação de outros exames de prénatal, também sem os devidos esclarecimentos e consentimento, revela uma postura profissional predominante nos serviços e falhas na assistência, notória na inadequada relação profissional de saúdeusuário.

No presente estudo, embora todas as parturientes entrevistadas tenham se consultado no pré-natal, a demora na realização da testagem para HIV, entre aquelas atendidas pelo SUS, sugere problemas organizacionais e de fluxo, tais como demora na coleta de sangue e no encaminhamento das amostras ao laboratório de referência, ou demanda reprimida por insuficiência de cotas de exames.

$\mathrm{O}$ caso da atenção às gestantes revela-se como traçador da realidade do sistema de atenção à saúde no país e mais especificamente na Regional de Saúde estudada. Os resultados aqui obtidos permitem inferir que a fragilidade observada se reproduza em várias áreas programáticas tradicionalmente instituídas no país. A compreensão da atenção aos grupos populacionais mais vulneráveis, aí incluindo o grupo materno-infantil, na lógica da vigilância da saúde, pressupõe a necessidade de as Regionais de Saúde, na qualidade de instância administrativa de nível intermediário, implementarem as políticas de prevenção e controle. É assumir, conforme destacam Vasconcelos e Hamann, 16 a coordenação pelo desenvolvimento de ações cabíveis na estrutura e processo de trabalho, que permitam aos municípios contemplar o alcance dos patamares factíveis dos coeficientes de transmissão vertical. A Saúde da Família, hoje implantada em municípios da região estudada, representa mecanismo estratégico de monitoramento e prevenção da transmissão vertical, que poderá tornar-se efetivo e legitimar-se mediante atuação da Regional de Saúde no desenvolvimento dos profissionais envolvidos e na organização e administração do programa.

\section{Referências}

1. UNAIDS (Joint United Nations Programme on HIV/Aids). Aids epidemic update: december 2002. Available from: http://www.unaids.org/html/pub/Topics/Epidemiology/ RegionalEstimates2002 [2003 Sept 23].

2. Brasil. Ministério da Saúde. Programa Nacional de DST/Aids. Desafios futuros: metas para o combate à AIDS de 2003 a 2006. Disponível em URL: http://www.aids.gov. br/final/biblioteca/metas/metas.pdf [2003 set 17]

3. Brasil. Ministério da Saúde. Comentários. Bol Epidemiol Aids. 2002; 16: 2-3.

4. Bertolli J, Louis MES, Simonds RJ, Nieburg P, Kamenga M, Brown C, Tarande M, Quinn T, Ou CY. Estimating the timing of mother-to-child transmission of human immunodeficiency virus in a breast-feeding population in Kinshasa, Zaire. J Infect Dis. 1996; 174: 722-6.

5. Tess BH, Rodrigues LC, Newell ML, Dunn DT, Lago TD Breastfeeding, genetic, obstetric and other risk factors associated with mother-to-child transmission of HIV-1 in São Paulo State, Brasil. AIDS. 1998; 12: 513-20.
6. Connor EM, Sperling RS, Gelber R, Kiselev P, Scott G, O'Sullivan MJ, VanDyke R, Bey M, Shearer W, Jacobson RL, Jimenez E, O'Neill E, Bazin B, Delfraissy J-F, Culnane M, Coombs R, Elkins M, Moye J, Stratton P, Balsley J. Reduction of maternal-infant transmission of human immunodeficiency virus type 1 with zidovudine treatment. N Engl J Med. 1994; 331:1173-80.

7. Mandelbrot L, Landreau-Mascaro A, Rekacewicz C, Berrebi A, Bénifla JL, Burgard M, Lachassine E, Barret B, Chaix M-L, Bongain A, Ciraru-Vigneron N, Crenn-Hérbert C, Delfraissy J-F, Rouzioux C, Mayaux M-J, Blanche S. Lamivudine-zidovudine combination for prevention of maternal-infant transmission of HIV-1. JAMA. 2001; 285: 2083-93.

8. Ioannidis JPA, Abrams EJ, Ammann A, Bulterys M, Goedert JJ, Gray L, Korber BT, Mayaux MJ, Mofenson LM, Newell M-L, Shapiro DE, Teglas JP, Wilfert CM. Perinatal transmission of human immunodeficiency virus type 1 by pregnant women with RNA virus load $<1000$ copies $/ \mathrm{ml}$. J Infect Dis. 2001; 183: 539-45. 
9. Mandelbrot L, Chenadec J, Berrebi A, Bongain A, Bénifla JL, Delfraissy J-F, Blanche S, Mayaux M-J. Perinatal HIV-1 transmission. Interaction between Zidovudine prophylaxis and mode of delivery in the French perinatal cohort. JAMA. 1998; 280: 55-60.

10. OPS (Organización Panamericana de la Salud) Recommendations on the use of antiretroviral agents in pregnant women infected with HIV-1. Rev Panam Salud Publica. 2001; 9: 345-54

11. Brasil. Ministério da Saúde. Gabinete do Ministro. Portaria n. 874, de 03 de julho de 1997: publica o guia de condutas terapêuticas em HIV/DST, para orientar o cumprimento do disposto nos parágrafos $1^{\circ}$ e $2^{\circ}$ da Lei n. 9.313, de 13/11/96. Diário Oficial da União; 1997; 126. Disponível em: www.saude.gov.br/legisla/legisla/legisla/aids/GM_874_97a ids.doc [2003 set 20].

12. Nicoll A, McGarrigle C, Brady AR, Ades AE, Tookey P, Duong T, Mortimer J, Cliffe S, Goldberg D, Tappin D, Hudson C, Peckham C. Epidemiology and detection of HIV-1 among pregnant women in the United Kingdom: results from national surveillance 1988-1996. BMJ. 1998; 316: $253-8$.

13. UNAIDS (Joint United Nations Programme on HIV/Aids). Informe sobre la epidemia mundial de VIH/SIDA 2002. Available from: http://www.unaids.org/html/pub/GlobalReports/Barcelona/BRGlobal-AIDS-Report-sp-pdf/BR [2003 Oct 01]

14. Capobiango JD. Avaliação da prevalência da infecção pelo vírus da imunodeficiência humana, por intermédio da realização do teste rápido, em 4341 parturientes de Londrina, PR [dissertação mestrado]. Londrina: Centro de Ciências da Saúde da Universidade Estadual de Londrina; 2002.

15. Morimura MCR, Mendes MDC Souza AI, Alencar LCA. Freqüência de testagem rápida para o HIV durante a admissão para o parto em puérperas no Instituto Materno Infantil Prof. Fernando Figueira, IMIP. Rev Bras Saúde Matern Infant. 2006; 6 (Supl 1): 569-76.

16. Vasconcelos ALR, Hamann EM. Por que o Brasil ainda registra elevados coeficientes de transmissão vertical do HIV? Uma avaliação da qualidade da assistência prestada a gestantes/parturientes infectadas pelo HIV e seus recémnascidos. Rev Bras Saúde Matern Infant. 2005; 5: 483-92.

17. Brasil. Ministério da Saúde. Datasus. População residente segundo regional de saúde Maringá. 2003. Disponível em URL: http://tabnet.datasus.gov.br/cgi/tabcgi.exe?ibge/cnv/ poppr.htm [2003 ago 29].
18. SINASC (Sistema de Informações sobre Nascidos Vivos). Décima quinta Regional de Saúde do Paraná [dados sobre nascidos vivos por escolaridade e idade maternas]. Maringá, 2002.

19. Brasil. Ministério da Saúde. Informações de saúde. Brasília, DF; 2000. Disponível em: http://tabnet.datasus.gov.br/cgi/ tabcgi.exe?ibge/cnv/alfpr.def. [2003 ago 28].

20. Feliciano KVO, Kovacs MH. Vulnerabilidade programática na prevenção da transmissão materno-fetal da AIDS. Rev Bras Saúde Matern Infant. 2002; 2: 157-65.

21. Neves FRAL, Passos ADC, Gueleri WL. Disponibilidade de sorologia anti-HIV como um teste voluntário na rotina do atendimento pré-natal em unidades básicas de saúde. Rev Saúde Pública. 1999; 33: 624-5.

22. Goldani MZ, Giugliani ERJ, Scanlon T, Rosa H, Castilhos K, Feldens L, Tomkins A. Voluntary HIV counseling and testing during prenatal care in Brazil. Rev Saúde Pública. 2003; 37: 552-8.

23. CDC (Centers for Disease Control and Prevention). Prenatal discussion of HIV testing and maternal HIV testing - 14 states, 1996 - 1997. Morb Mortal Wkly Rep. 1999; 48: 401-4.

24. CDC (Centers for Disease Control and Prevention). Current trends characteristics of and HIV infection among women served by publicly funded HIV counseling and testing services-United States, 1989-1990. Morb Mortal Wkly Rep. 1991; 40: 195-6.

25. Bitnun A, King SM, Arneson C, Read SE. Failure to prevent perinatal HIV infection. CMAJ. 2002; 166: 904-6.

26. Remis RS, Patrick DM. Access to prenatal HIV testing. CMAJ. 1998; 158: 1469-70.

27. Kumar A, Rocheste E, Gibson M, Gibson T, Robinson H, Forde S. Antenatal voluntary counseling and testing for HIV in Barbados: success and barriers to implementation. Rev Panam Salud Publica. 2004; 15: 242-8.

28. Brasil. Ministério da Saúde. Secretária de Vigilância à Saúde. Programa Nacional DST/Aids. Recomendações para profilaxia da transmissão vertical do HIV e terapia antiretroviral em gestantes. Brasília, DF; 2004. Disponível em URL: http://bvsms.saude.gov.br/bvs /aids/publicacoes /ConsensoGestante2004.pdf [2007 fev 28].

29. Ayres JRCM, França Jr I, Calazans GJ, Saletti Filho HC. Vulnerabilidade e prevenção em tempos de AIDS. In: Barbosa RM, Parker R. Sexualidades pelo avesso: direitos, identidades e poder. Rio de Janeiro: Ed. 34; 1999. p. 49-72.

Recebido em 6 de março de 2007

Versão final apresentada em 30 de novembro de 2007

Aprovado em 5 de dezembro de 2007 